\title{
A ten year analysis of maternal deaths in a tertiary hospital using the three delays model
}

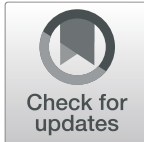

Mo'men M. Mohammed', Saad El Gelany ${ }^{1 *}$ (D, Ahmed Rida Eladwy', Essam Ibrahium Ali ${ }^{1}$, Mohamed T. Gadelrab', Emad M. Ibrahim ', Eissa M. Khalifa', Ahmed K. Abdelhakium ', Hashem Fares', Ayman M. Yousef ', Heba Hassan', Khaled Goma', Mahmoud H. Ibrahim', Alaa Gamal', Mohamed Khairy', Ahmed Shaban², Sahar Amer', Ahmed R. Abdelraheim ${ }^{1}$ and Ameirr A. Abdallah ${ }^{1}$

\begin{abstract}
Background: Reducing maternal mortality ratios (MMRs) remain an important public health issue in Egypt. The three delays model distinguished three phases of delay to be associated with maternal mortality: 1) first phase delay is delay in deciding to seek care; 2) second phase delay is delay in reaching health facilities; and 3) third phase delay is delay in receiving care in health facilities. Increased health services' coverage is thought to be associated with a paradigm shift from first and second phase delays to third phase delay as main factor contributing to MMR.

This study aims to examine the contribution of the three delays in relation to maternal deaths.
\end{abstract}

Methods: During a 10 year period (2008-2017) 207 maternal deaths were identified in a tertiary hospital in Minia governorate, Egypt. Data were obtained through reviewing medical records and verbal autopsy for each case. Then data analysis was done in the context of the three delays model.

Results: From 2008 to 2017 MMR in this hospital was 186/100.000 live births. Most frequent causes of maternal mortality were postpartum hemorrhage, hypertensive disorders of pregnancy and sepsis.

Third phase delay occurred in 184 deaths (88.9\%), second phase delay was observed in 104 deaths (50\%), always together with other phases of delay. First phase delay alone was observed in 13 deaths (6.3\%) and in 82 deaths $(40 \%)$ with other phases of delay. One fifth of the women had experienced all three phases of delay together. Major causes of third phase delay were delayed referral from district hospitals, non-availability of skilled staff, lack of blood transfusion facilities and shortage of drugs.

Conclusions: There is a paradigm shift from first and second phases of delay to the third phase of delay as a major contributor to maternal mortality. Reduction of maternal mortality can be achieved through improving logistics, infrastructure and health care providers' training.

Trial registration: This study is a retrospective study registered locally and approved by the ethical committee of the Department of Obstetrics and Gynaecology, Minia University Hospital on 1/4/2016 (Registration number: MUEOB0002).

Keywords: Three delays model, Minia, Egypt, Maternal mortality

\footnotetext{
* Correspondence: Saad.elgelany@yahoo.co.uk; Saad.Elgelany@mu.edu.eg;

Saadelgelany@gmail.com

'Obstetrics and Gynecology Department, Faculty of Medicine, Minia

Maternity and Children University Hospital, Minia University, Elsalam, Eloboor,

Maghaghaga City, Minia, Egypt

Full list of author information is available at the end of the article
}

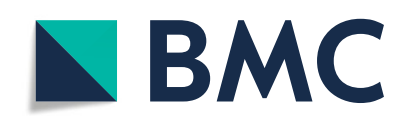

(- The Author(s). 2020 Open Access This article is licensed under a Creative Commons Attribution 4.0 International License, which permits use, sharing, adaptation, distribution and reproduction in any medium or format, as long as you give appropriate credit to the original author(s) and the source, provide a link to the Creative Commons licence, and indicate if changes were made. The images or other third party material in this article are included in the article's Creative Commons licence, unless indicated otherwise in a credit line to the material. If material is not included in the article's Creative Commons licence and your intended use is not permitted by statutory regulation or exceeds the permitted use, you will need to obtain permission directly from the copyright holder. To view a copy of this licence, visit http://creativecommons.org/licenses/by/4.0/. The Creative Commons Public Domain Dedication waiver (http://creativecommons.org/publicdomain/zero/1.0/) applies to the data made available in this article, unless otherwise stated in a credit line to the data. 


\section{Background}

Maternal mortality is an indicator of many parameters of maternal health, such as women's status, access to care and quality of care in low resource settings [1]. Complications during pregnancy, labour and puerperium account for 303,000 women dying every year. Most deaths (99\%) occur in low resource settings, especially in South Asia and sub-Saharan Africa [2]. Most deaths are preventable [3]. The maternal mortaility ratio (MMR) for Egypt in 2015 was 39/100000 [4].

Two key evidence based interventions to reduce maternal morbidity and mortality include access to Skilled Birth Attendance (SBAs) with enabling environment during labour and basic and comprehensive Emergency Obstetric and Neonatal Care (EmONC) [5]. The five direct causes of maternal mortality are obstetric hemorrhage, hypertensive disorders of pregnancy, obstructed labour, sepsis and complications of unsafe abortion, responsible for nearly two-thirds of deaths worldwide [6].

In 1994, Thaddeus and Maine's three delays model has been introduced as an effective tool to evaluate circumstances surrounding access to and appropriateness of EmONC [7]. This model identifies barriers and intervention points during the woman's pathway from home to hospital [8]. First phase delay which occurs at household and community level, reflects delay in deciding to seek care for pregnancy and birth complications. Second phase delay refers to delay to reach the facility and third phase delay refers to delay that happens in the health facility [9].

A recent study in Malawi showed that third phase delay was found in $96.8 \%$ of maternal deaths compared to $59.6 \%$ first phase and $39.7 \%$ second phase delays [10].

Regular annual analysis of maternal deaths in Minia university maternity hospital over a 10 years period identified different delays and subsequently addressing the findings can help to implement adequate interventions to reduce maternal mortality.

In this study, the three delays model is used to investigate different delays associated with maternal mortality that occurred in our tertiary hospital.

\section{Methods}

\section{Study settings}

This is an institution-based, retrospective study in Minia Maternity and Children University Hospital, Minia governorate, Egypt. Data collection was done between January 2008 and December 2017.

Minia governorate is located in Upper Egypt with an estimated population of 5.5 million in 2017 [11] . Administratively, Minia governorate is divided into nine major cities. There are three levels of health services in this governorate: primary, secondary and tertiary level.
The first level is served by primary health care units while secondary care is served by nine general hospitals and the private sector. Each general hospital covers an average population of 600.000 inhabitants and has one to two ambulances to serve the surrounding primary health care units and the tertiary hospital. The nine general hospitals have capacity to offer Basic Emergency Obstetric Care (BEmONC). Tertiary level care is provided by Minia maternity university hospital. The private sector deals with the majority of cases followed by the public hospitals and all served by one tertiary hospital which is located nearly in the middle of the governorate along the 135 Kilometres road alongside the river Nile. The different layers of care are connected by a referral system based on personal relationships, private cars and ambulances managed by the general hospitals.

\section{Study population}

All maternal deaths in Minia hospital during the study period were collected using structured form designed by the researchers to collect relevant information using multiple sources of data. These included vital registration, health facility records, burial records, and interviews with family members (verbal autopsy), physicians involved in the care during pregnancy and traditional birth attendants (TBAs).

The current research project was performed in two steps. The first stage involved detection of all maternal deaths using multiple sources. Then all deaths were examined in the second stage (using verbal autopsy, health service reports or case notes, death certificates documenting time and cause of death and interviews with family members and relatives).

To ensure data quality and to avoid missing any deaths, the research team visited registration department in the hospital once a month and again at the end of the study period, cross-checked all registers to identify any deaths not yet reported. At the end of every month, lists from the three data sources (maternal mortality meeting reports, ministry of health reports and hospital files) were compared and any duplicates removed.

Maternal death was defined according to ICD-10 as: "The death of a woman while pregnant or within 42 days of termination of pregnancy irrespective of the duration and the site of the pregnancy, from any cause related to or aggravated by the pregnancy or its management but not from accidental or incidental causes" [12].

Trained research staff visited all households in which maternal death had occurred to interview all persons (including relatives, TBAs, primary health care staff and neighbours) who had knowledge of the woman's illness and death using a standard verbal autopsy questionnaire designed by the ministry of health according to WHO 
format [13]. They prepared a separate report for each case of maternal death that has been reviewed by an expert panel to assess its underlying cause of death and factors associated with each case.

\section{Data collection}

Data included age, parity, booking status, referral source, possible cause of death and substandard care factors, time of arrival in the emergency room, as well as time of treatment initiation with a medical or surgical intervention, time of death, care received in the periconceptional and perinatal period, place of birth, decisions taken by health care providers involved in care (e.g. obstetricians, general practitioners?, midwives? TBAs, ....), journey from home to health facility, referral status, and impression of the care perceived from the relatives about its quality provided in the health facility.

Each case was assigned with a single underlying cause of death. For each maternal death, data sheets were created using all documents, including any medical records, all verbal autopsy information, medical personnel interviews and/or information obtained through a maternal death review conducted at the health facility.

Data were reviewed by a committee of experts composed of seven Ob/Gyn consultants affiliated to Minia University in addition to a representative from the maternal mortality counsel of the ministry of health. The committee reviewed the circumstances of each death to determine: 1) underlying cause of death which initiated the chain of events that ultimately led to death of the woman, 2) Any evidence suggesting delay at various levels [7]. Data regarding first and second phase delay were obtained from interviews with patients' relatives whereas that regarding the third phase delay was taken from the case files and interviews of the physicians involved in the care.

A note was made of substandard care factors which could have contributed significantly to maternal deaths. Substandard care was defined as care received by the woman falling below the standard that should have been offered to her in accordance with the agreed local protocols in our institution.

\section{Application of the three delays model}

The second phase delay involved delay in transfer from different health facilities and numerous referrals while delay in seeking medical care due to family or community factors was considered as a first-phase delay. Delay in reaching the health facility with the capacity to provide basic emergency obstetric care services is a secondphase delay. Women who faced delay in the process of referral to the second health facility were known as second phase delay. If evidence indicates delay in providing sufficient health care inside the health facility (i.e. general hospitals, private sectors or Minia teriary hospital), it is classified as a third phase delay. Delay was described on the basis of evaluating the individual story of each woman since her arrival at the original health facility.

All data were independently checked by the research team. Key themes were identified and used for the creation of a structured analytical form to define each phase of delay: first phase delay (lack of financial support, unavailability of husband, lack of knowledge of obstetric risks, social problems, previous uncomplicated pregnancy, previous poor health facility experience or perceived poor quality of care in the health facility, avoiding admissions). Second phase delay (Absence of a local health facility, travel costs, bad road conditions, long distance to the nearest hospital, availability of TBAs), third phase delay (long waiting period prior to receipt of treatment (more than $30 \mathrm{~min}$ from the time of arrival to the time of assessment or care), lack of equipment and resources, unavailability of health care providers, absecne of experienced staff, lack of infrastructure, shortage of medicines and necessary medications, incorrect risk assessment, inaccurate diagnosis and treatment, lack of a referral system, lack of treatment policies). In one particular instance, there might have been one or more delays. Then, all cases were examined jointly. In the event of disagreement, joint meetings with analysis of the issues of disagreement were held before consensus was reached.

\section{Statistical analysis}

Data were analysed by computer software, SPSS version 20 , and results presented as frequencies and percentages.

\section{Results}

A total of 207 maternal deaths were identified in the study setting, out of 107,444 deliveries and 110,766 live births, during the period of study corresponding to a facility based maternal mortality ratio of 186 deaths per 100.000 live births (95\% CI: 162-213).

Over 10-years (2008-2017), the women who died, had a mean age of $28.8 \pm 6.2$ years with a range between 18 and 40 years. Only $15(7.2 \%)$ were $<20$ years and 10 $(4.8 \%)$ were $\geq 40$ years. Most women were multiparous (159; 76.8\%) while 48 (23.2\%) were primiparas and 92 women $(44.4 \%)$ had no formal education.

Almost three quarters $(152 ; 73.4 \%)$ of the maternal deaths had attended $\geq 4$ ANC visits, while only 15 women (7.2\%) did never attend ANC. Most of them (170 women) (80\%) received ANC in the private sector, while only 20 women $(9.9 \%)$ were booked in primary health care facilities. In the study setting hospital only six women $(2.9 \%)$ were booked. 
The majorty of women died within $24 \mathrm{~h}$ after birth (85 women, $41 \%$ ). About one third of women died after the first $24 \mathrm{~h}$ till the end of puerperium (60 women, $29 \%)$.Thirty three women (15.9\%) died during birth and 29 women (14\%) died during pregnancy.

Most frequent causes of direct maternal mortality were postpartum hemorrhage (24.6\%), hypertensive disorders of pregnany (19.8\%) and sepsis (9.7\%). Most common cause of indirect maternal mortality was cardiac diseases (6.3\%) (Table 1).

Almost one third of the women who eventually died, were referred from general hospitals, one quarter was directly admitted to the tertiary hospital and one quarter came from home after being managed by TBAs (home care), while the private sector referred one fifth (Table 2). Referred women to the tertiary hospital from the private and/or public hospitals were primarily attended by TBAs and/or primary health care physicians.

Time between admission and death ranged from 0 to $572 \mathrm{~h}$ with a median of 14 days (IQR 10.2 days). Fourteen

Table 1 Underlying cause of death

\begin{tabular}{|c|c|}
\hline Cause & N (\%) \\
\hline Direct maternal deaths & $162(78.3 \%)$ \\
\hline Postpartum haemorrhage & $51(24.6 \%)$ \\
\hline Hypertensive disorders of pregnancy & $41(19.8 \%)$ \\
\hline - Eclampsia & $21(10.1 \%)$ \\
\hline - Severe preeclampsia & $20(9.7 \%)$ \\
\hline Sepsis & $20(9.7 \%)$ \\
\hline Thromboembolism & $12(5.8 \%)$ \\
\hline Anaesthetic complications & $9(4.3 \%)$ \\
\hline Uterine rupture & $7(3.5 \%)$ \\
\hline Placenta previa & $5(2.4 \%)$ \\
\hline Placental abruption & $4(1.9 \%)$ \\
\hline Hyperemesis gravidarum & $4(1.9 \%)$ \\
\hline Suspected amniotic fluid embolism & $3(1.4 \%)$ \\
\hline Ectopic pregnancy & $2(1.0 \%)$ \\
\hline Molar pregnancy & $2(1.0 \%)$ \\
\hline Acute uterine inversion & $2(1.0 \%)$ \\
\hline Indirect maternal deaths & $42(20.3 \%)$ \\
\hline Cardiac disease & $13(6.3 \%)$ \\
\hline Hepatic diseases & $10(4.9 \%)$ \\
\hline Chronic chest diseases & $6(2.9 \%)$ \\
\hline Malignancy & $5(2.4 \%)$ \\
\hline Chronic renal diseases & $5(2.4 \%)$ \\
\hline Idiopahic thrombocytopenic purpura & $3(1.4 \%)$ \\
\hline Other causes $^{\mathrm{a}}$ & $3(1.4 \%)$ \\
\hline Total & 207 (100\%) \\
\hline
\end{tabular}

${ }^{a}$ Other causes include two cases of ovarian hyperstimulation syndrome (OHSS) and one case with anaphylactic reaction women died immediately on arrival and another fourteen died within $2 \mathrm{~h}$ after failed resuscitation, while fiftyseven women died within $24 \mathrm{~h}$ of admission.

\section{Phases and frequencies of delays}

The majority of women suffered from multiple phase delays $(58.9 \%)$, while the rest $(41.1 \%)$ had separate forms of delays (first \& third phase). Second phase delay never occurred on its own (Fig. 1). Third phase delay was present in almost $88.9 \%$ either alone or in conjunction with other phases of delay (Table 3). Reasons of referral to the tertiary hospital are presented in Table 4 .

\section{Discussion}

In the current study, the MMR from 2008 to 2017 was $186 / 100.000$ live births which is remarkably higher than has to be achieved by SDGs [14]. This hospital based MMR is almost five times higher than the national MMR for Egypt which was 39/100000 live births in 2015 [4]. This may be explained by the fact that Minia university hospital is a tertiary referral centre and complicated cases in the whole Minia governorate are referred to the hospital. A hospital based study about maternal mortality was conducted in Assiut governorate (Egypt) which is very near to Minia governorate with similar circumstances. MMR in Women Health Hospital, Assiut University, Egypt between 2009 and 2014 was 180/100.000 which is very similar to what was reported in our study [15].

All three phases of delay were present in 40 women (19.3\% of maternal deaths). The most frequent delay occurred in the third phase. This occurred alone in 34\% and in $88.9 \%$ in conjunction with the other two phases of delay. A similar study in Malawi found that third phase delay was encountered in $96.8 \%$ of maternal deaths [10]. Poor outcome has been shown to be associated with each phase of delay [16]. Substandard care was present in all three phases of delay in all health facilities [7].

All contributing factors to maternal mortality in our study are similar to findings in other studies in Malawi, Nigeria, Zambia, the Gambia, Ethiopia and Indonesia $[10,17-22]$.

A well-functioning health system should provide effective and efficient care through skilled health care providers in well-equipped health facilities with essential

Table 2 Place of care before death

\begin{tabular}{ll}
\hline Place of care before death & $\mathrm{N}(\%)$ \\
\hline Private place & $40(19.3 \%)$ \\
Home care & $50(24.2 \%)$ \\
General hospital & $66(31.9 \%)$ \\
University hospital & $51(24.6 \%)$ \\
\hline
\end{tabular}




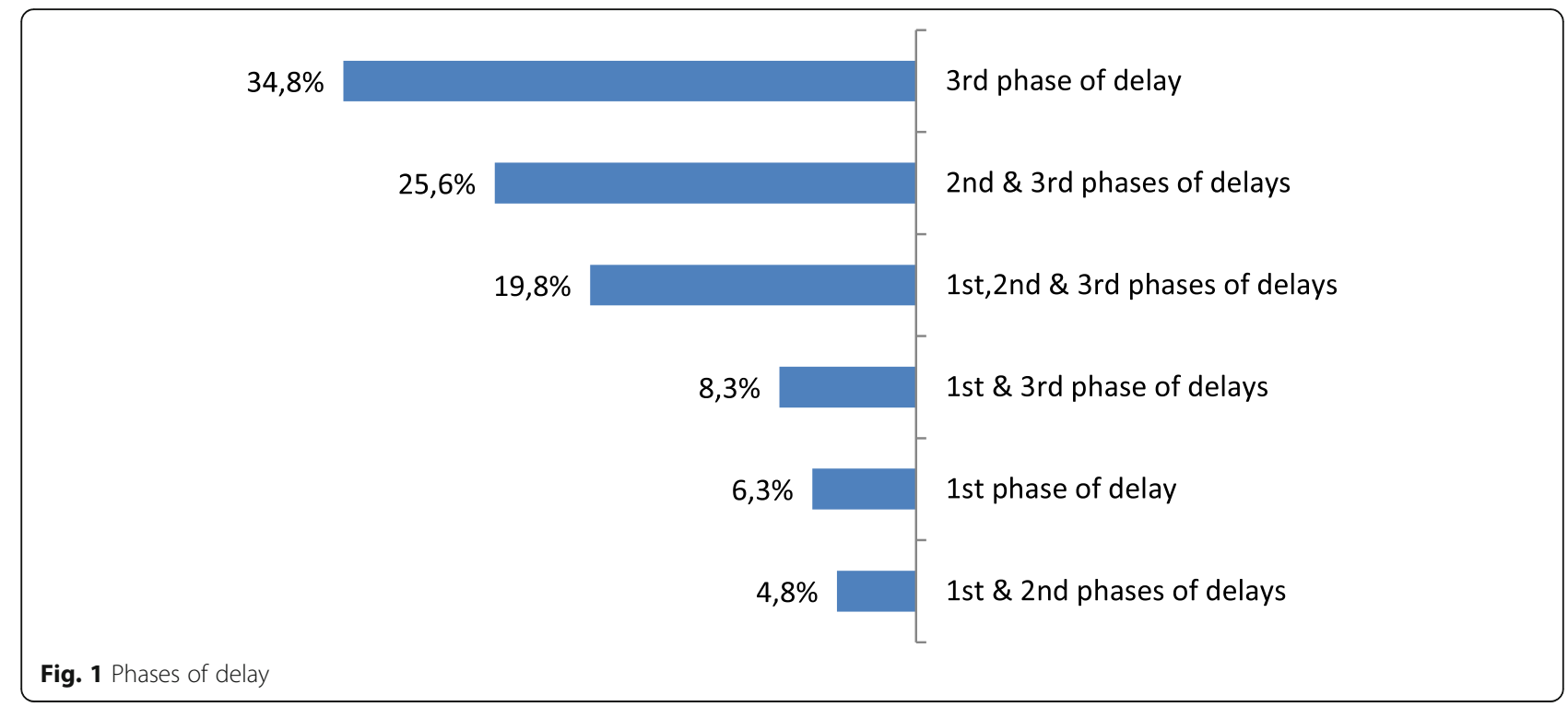

Table 3 Three phases of delay $(n=207)$

\begin{tabular}{|c|c|c|}
\hline Phase of delay & Causes & $\mathrm{N}(\%)$ \\
\hline \multirow{9}{*}{$\begin{array}{l}\text { First phase delay } \\
\text { (82 cases) } \\
(39.6 \%)\end{array}$} & Lack of awareness of obstetric complications & 40 (19.3\%) \\
\hline & Low status (women not financially empowered and/or non availability of husband). & $30(14.5 \%)$ \\
\hline & Uneventful previous home births. & $30(14.5 \%)$ \\
\hline & Previous bad experience of health care & $20(9.7 \%)$ \\
\hline & Perceived poor quality of care in healthcare facilities & $25(12.1 \%)$ \\
\hline & Low family income & $28(13.5 \%)$ \\
\hline & Visited TBAs or unexperienced physician. & $45(21.7 \%)$ \\
\hline & Long waiting in a healthcare facility & $10(4.8 \%)$ \\
\hline & Domestic violence & $10(4.8 \%)$ \\
\hline \multirow{6}{*}{$\begin{array}{l}\text { Second phase delay } \\
\text { (104 cases) } \\
(50.2 \%)\end{array}$} & Late referral to the tertiary hospital & $50(24.2 \%)$ \\
\hline & Multiple referrals & $39(18.8 \%)$ \\
\hline & Home -Health facility Long distance. & $29(14 \%)$ \\
\hline & Lack of a health facility in the area & $50(24.2 \%)$ \\
\hline & Poor or inaccessible road conditions. & $10(4.8 \%)$ \\
\hline & High costs of transport & $5(2.4 \%)$ \\
\hline \multirow{8}{*}{$\begin{array}{l}\text { Third phase delay } \\
\text { (184 cases) } \\
(88.9 \%)\end{array}$} & Inadequate referral system & $100(48.3 \% /)$ \\
\hline & Senior staff unavailable & $110(53.1 \%)$ \\
\hline & Shortage of equipment and supplies & $60(29 \%)$ \\
\hline & Lack of competence on EmOC in health facilities & $110(53.1 \%)$ \\
\hline & Wrong assessment (of risk, diagnosis, treatment) & $63(30.4 \%)$ \\
\hline & Lack of treatment guidelines & $40(19.3 \%)$ \\
\hline & Shortage of trained staff & $67(32.4 \%)$ \\
\hline & Long waiting time before treatment in health facility & $14(6.8 \%)$ \\
\hline
\end{tabular}


Table 4 Reasons of referral to the tertiary hospital (N 156= 75.4\%)

\begin{tabular}{ll}
\hline Reason & $\mathrm{N}(\%)$ \\
\hline Non -availability of blood & $110(53 \%)$ \\
Non-availability of intensive care unit (ICU) & $70(33.8 \%)$ \\
Non-availability of anaesthetists & $64(30.9 \%)$ \\
Non-availability of skilled personel & $33(15.9 \%)$ \\
Shortage of equipment and supplies & $134(64.7 \%)$ \\
\hline
\end{tabular}

medications and equipment. That has been prescribed by Adegoke et al. as "enabling environment" [23].

In a study conducted in Mozambique's Maputo Province, covering 564 surviving women and 71 maternal deaths, second phase delay occurred in $21.3 \%$ and third phase delay in $69.7 \%$ of cases $[24,25]$. In the same study, these delays followed the woman's path throughout the referral system from admission to a peripheral health facility on to the terminal referral hospital [25].

Sometimes instability in the security situations in Egypt led to second phase delay in referral from home to hospitals. In Malawi, fuel shortage led to delay in referral to health facilities $[10,26]$. Lack of proper referral system has been reported as a cause contributing to $25 \%$ of maternal deaths in some studies [26]. In the Gambia, use of ambulances for others purposes forced women to seek alternatives and to pay for transport [27]. Absence of emergency obstetric care also has been reported to be a major cause of maternal mortality with a frequency reaching up to $60 \%$ of maternal deaths in some studies in low and middle income countries [28-30]. Facilities providing EmONC may be extremely far from women's homes. Maternity waiting homes (MWH) have been proposed as strategy to overcome inaccessability [31]. MWHs are places with easy access to hospital in which women with high risk pregnancies near term await birth to assure easy admission to hospital once labour starts or complications like hemorrhage arise. We think that MWHs could be beneficial in our locality as the " health facility's long distance" was implicated in $14 \%$ of maternal deaths in our study.

In our study, first and second phase delays were experienced less frequently than third phase delay. Poor quality of care may influence women's decisions to access care [32].

Remarkably the great majority of women who died had attended some form of ANC, while only $7.2 \%$ did not attended even once. This is paradoxical to other studies, in which most maternal deaths occurred in unbooked women [33-35]. This paradox is in agreement with official reports of the Egyptian ministry of health and may be explained from the point of view that women with high risk pregnancies receive ANC while women with low risk pregnancies do not book for ANC.
An additional factor is the lack of standard ANC with its poor quality.

Women in our study still faced important risks of dying, even when they arrived directly in the health facility, being in a healthier status [5]. Third phase delay was implicated in the majority of maternal deaths in our study.

\section{Strengths and limitation}

Being the first study in Egypt to apply the three phases delay model to analyse maternal mortality in a 10 years period in a large tertiary hospital is one of the strengths of this study. This can be replicated in other governorates in Egypt, which can provide policy managers with data to plan appropriate health interventions for reduction of maternal mortality. Another strong point is the analysis by the expert group that helped to reduce inconsistencies in the data from the files.

There were limitations as well. Limiting data to one health facility, being a tertiary hospital in one Egyptian governorate limits generalization to the rest of the country due to different geographic patterns even in the same country. Also, inclusion of a control group of women who survived, would possibly have clarified other determinants of maternal mortality. Although many sources for data collection were available, the quality of hospital and health centre registers and medical charts were poor, especially for data about ANC. Another limitation to take into account is the fact that this study is " institution based", so maternal deaths at home or in general and private hospitals are not studied here.

Regarding implications of the current study, there is an urgent need for reinforcing the referral pathways between hospitals and optimising the hospital needs with equipment to provide timely and adequate care in a friendly manner with respect to women as prerequisites to save the lives of women and newborns.

\section{Conclusions}

The current study provides policy makers with clues to initiate interventions and recommendations to reduce maternal mortality at different levels of care, also in similar national and international settings. There is a paradigm shift from first and second phases of delay to the third phase of delay as a major contributor to maternal mortality. Inadequate referral system, senior staff unavailability and lack of competence on basic and comprehensive EmOC are implicated in 50\% of maternal deaths, all of them modifiable factors. This will need urgent improvements in the whole maternal health system.

\section{Abbreviations}

ANC: Antenatal Care; BEmOC: Basic Emergency Obstetric Care; EmOC: Emergency Obstetric Care; EmONC: Emergency Obstetric and Neonatal Care; HTN: Hypertensive disorders; IQR: Interquartile range; 
MMRs: Maternal mortality ratios; OHSS: Ovarian hyperstimulation syndrome; SBAs: Skilled Birth Attendants; TBAs: Traditional Birth Attendants; $\mathrm{MWH}$ : Maternity waiting home

\section{Acknowledgements}

The authors wish to thank Professors Mohamed Hany, Mohamed Abdallah, Neveen M Noureldin, and Hossam Eldin Shawky (head of the department), for their valuable contributions and advice during preparation of the manuscript. Our sincere gratitude goes to the management staff of the faculty of Medicine, Minia maternity and children university hospital during the study period for their support and for assisting with data collection.

\section{Authors' contributions}

All authors made a significant contribution to the manuscript. SG, AA2, AE, EA and HF conceptualized the study. SG, MG, MM, EK, AA1, AY, HH, KG, MI and AA2 were involved in the primary research concept and design of the study, initial data collection, writing, and data analysis. All authors participated in the study design, planning of analysis, and interpretation of results. MM, SG, El, MI, AG, MK, SA, AA2, AA3 and AS performed the literature review and drafted the manuscript. All authors have read and approved the manuscript.

\section{Funding}

No funding was received for this study.

\section{Availability of data and materials}

The datasets used and/or analyzed during the current study are available from the corresponding author on reasonable request.

\section{Ethics approval and consent to participate}

The research project was approved by the ethical committee of the Department of Obstetrics and Gynaecology, Minia University Hospital on 1/ 4/2016 (Registration number: MUEOB0002). Consent to participate is not applicable as this study reviews secondary aggregated data.

\section{Consent for publication}

Not applicable.

\section{Competing interests}

The authors declare that they have no competing interests.

\section{Author details}

'Obstetrics and Gynecology Department, Faculty of Medicine, Minia Maternity and Children University Hospital, Minia University, Elsalam, Eloboor, Maghaghaga City, Minia, Egypt. ²Masr Elhurra Hospital, Minia Directorate of Health, Minia, Egypt. ${ }^{3}$ Minia General Hospital, Minia Directorate of Health, Minia, Egypt.

\section{Received: 27 December 2019 Accepted: 18 September 2020} Published online: 06 October 2020

\section{References}

1. McCaw-Binns A, Greenwood R, Ashley D, Golding J. Antenatal and perinatal care in Jamaica: do they reduce perinatal death rates? Paediatr Perinat Epidemiol. 1994;8(Suppl 1):86-97.

2. Kassebaum NJ, Bertozzi-Villa A, Coggeshall MS, Shackelford KA, Steiner C Heuton KR, et al. Global, regional, and national levels and causes of maternal mortality during 1990-2013: a systematic analysis for the Global Burden of Disease Study 2013. Lancet (London, England). 2014;384(9947): 980-1004.

3. Hunt $P$. The human right to the highest attainable standard of health: new opportunities and challenges. Trans R Soc Trop Med Hyg. 2006;100(7):603-7.

4. World Health Organization. Health in 2015: from MDGs-millennium development goals to SDGs-sustainable development goals. Geneva; 2015. ISBN 9789241565110

5. World Health Organization and Aga Khan University. Essential Interventions, Commodities and Guidelines for Reproductive, Maternal, Newborn and Child Health: A global review of the key interventions related to Reproductive, Maternal, Newborn and Child Health (RMNCH). Geneva: PMNCH, World Health Organization; 2011.
6. Some DT, Sombie I, Meda N. How decision for seeking maternal care is made--a qualitative study in two rural medical districts of Burkina Faso. Reprod Health. 2013;10:8.2013.

7. Thaddeus S, Maine D. Too far to walk: maternal mortality in context. Social Sci Med (1982). 1994;38(8):1091-110.

8. Betran AP, Wojdyla D, Posner SF, Gulmezoglu AM. National estimates for maternal mortality: an analysis based on the WHO systematic review of maternal mortality and morbidity. BMC Public Health. 2005;5:131.

9. $\mathrm{WHO}$. Beyond the numbers: reviewing maternal death and complication to make pregnancy and child brith safer. Geneva: WHO; 2004.

10. Mgawadere F, Unkels R, Kazembe A, van den Broek N. Factors associated with maternal mortality in Malawi: application of the three delays model. BMC Pregnancy Childbirth. 2017 Jul 12;17(1):219. https://doi.org/10.1186/ s12884-017-1406-5.

11. Sayed HA. Egypt's demographic opportunity (preliminary assessment based on 2017 census).UNFPA Egypt country office; 2018.

12. WHO. International statistical classification of diseases and related health problems. 10th revision. 2 vols. Geneva: WHO; 1992.

13. WHO. Verbal Autopsy Standards: 2012 WHO Verbal Autopsy Instrument Geneva: WHO; 2012

14. United Nations Sustainable development goals. United Nations 2015 https://www.un.org/pga/wpcontent/uploads/sites/3/2015/08/120815_ outcome-document-of-Summit-for-adoption-of-the-post2015-developmentagenda.pdf (Accessed 24 Sept 2017).

15. Abbas AM, Amin MT, Ali SS, Salem NZ. Maternal Mortality: a tertiary care hospital experience in upper Egypt. Int J Reprod Contracept Obstet Gynecol. 2016:5:1466-71.

16. Pacagnella RC, Cecatti JG, Parpinelli MA, Sousa MH, Haddad SM, Costa ML, et al. Delays in receiving obstetric care and poor maternal outcomes: results from a national multicentre cross-sectional study. BMC Pregnancy Childbirth. 2014;14:159

17. Combs Thorsen V, Sundby J, Malata A. Piecing together the maternal death puzzle through narratives: the three delays model revisited. PLoS One. 2012; 7(12):e52090.

18. Orji EO, Ojofeitimi EO, Esimai AO, Adejuyigbe E, Adeyemi AB, Owolabi OO Assessment of delays in receiving delivery care at a tertiary healthcare delivery Centre in Nigeria. J Obstet Gynaecol. 2006;26(7):643-4.

19. Stekelenburg J, van Roosmalen J. The maternal mortality review meeting: experiences from Kalabo District Hospital, Zambia. Tropical Doctor. 2002; 32(4):219-23.

20. Walraven G, Telfer M, Rowley J, Ronsmans C. Maternal mortality in rural Gambia: levels, causes and contributing factors. Bull World Health Organ. 2000;78(5):603-13.

21. Berhan $Y$, Berhan A. A meta-analysis of socio-demographic factors predicting birth in health facility. Ethiop J Health Sci. 2014;24(Suppl):81-92.

22. Supratikto G, Wirth ME, Achadi E, Cohen S, Ronsmans C. A district-based audit of the causes and circumstances of maternal deaths in South Kalimantan, Indonesia. Bull World Health Organ. 2002;80(3):228-34.

23. Adegoke AA, Hofman JJ, Kongnyuy EJ, van den Broek N. Monitoring and evaluation of skilled birth attendance: a proposed new framework. Midwifery. 2011 Jun;27(3):350-9.

24. Say L, Souza JP, Pattinson RC. Maternal near miss--towards a standard too for monitoring quality of maternal health care. Best Pract Res. 2009:23(3): 287-96.

25. David E, Machungo F, Zanconato G, Cavaliere E, Fiosse S, Sululu C, et al. Maternal near miss and maternal deaths in Mozambique: a cross-sectional, region-wide study of 635 consecutive cases assisted in health facilities of Maputo province. BMC Pregnancy Childbirth. 2014;14:401.

26. Barnes-Josiah D, Myntti C, Augustin A. The "three delays" as a framework for examining maternal mortality in Haiti. Soc Sci Med. 1998;46(8):981-93.

27. Cham M, Sundby J, Vangen S. Maternal mortality in the rural Gambia, a qualitative study on access to emergency obstetric care. Reprod Health. 2005 May 4;2(1):3.

28. Moodley J. Maternal deaths associated with eclampsia in South Africa: Lessons to learn from the confidential enquiries into maternal deaths, 2005-2007. S Afr Med J. 2010;100(11):717-9.

29. Essendi H, Mills S, Fotso JC. Barriers to formal emergency obstetric care services' utilization. J Urban Health. 2011:88(Suppl 2):S356-69.

30. Ameh C, Msuya S, Hofman J, Raven J, Mathai M, van den Broek N. Status of emergency obstetric care in six developing countries five years before the MDG targets for maternal and newborn health. PLoS One. 2012;12:e49938. 
31. Van Lonkhuijzen L, Stekelenburg J, van Roosmalen J. Maternity waiting facilities for improving maternal and neonatal outcome in low-resource countries. Cochrane Database Syst Rev. 2012;10:CD006759.

32. Killewo J, Anwar I, Bashir I, Yunus M, Chakraborty J. Perceived delay in healthcare-seeking for episodes of serious illness and its implications for safe motherhood interventions in rural Bangladesh. J Health Popul Nutr. 2006;24(4):403-12.

33. Uzabakiriho B, Maswime S. Causes of maternal death at Natalspruit Hospital, Johannesburg, South Africa. South African Med J. 2019;109(6):412-4.

34. Mittal P, Kapoor G, Kumari N, Bajaj B. Review of maternal mortality at a tertiary care hospital: what have we achieved? J Obstet Gynaecol India. 2019;69(2):149-54.

35. Bhadra B, Choudhury RR, Sarkar D, Sarkar S. An epidemiological study of mortality among mothers admitted in a rural tertiary hospital of West Bengal. J Matern Fetal Neonatal Med. 2018;21:1-161.

\section{Publisher's Note}

Springer Nature remains neutral with regard to jurisdictional claims in published maps and institutional affiliations.

Ready to submit your research? Choose BMC and benefit from:

- fast, convenient online submission

- thorough peer review by experienced researchers in your field

- rapid publication on acceptance

- support for research data, including large and complex data types

- gold Open Access which fosters wider collaboration and increased citations

- maximum visibility for your research: over $100 \mathrm{M}$ website views per year

At BMC, research is always in progress.

Learn more biomedcentral.com/submissions 